\title{
Academic persistence among nursing students: A concept analysis
}

\author{
Kimberly D. Kennel ${ }^{* 1}$, Peggy Ward-Smith ${ }^{2}$ \\ ${ }^{1}$ Baptist College of Health Sciences, United States \\ ${ }^{2}$ University of Missouri-Kansas City, United States
}

Received: April 20, 2017

DOI: $10.5430 /$ jnep.v7n11p62
Accepted: June 7, 2017

URL: https://doi.org/10.5430/jnep.v7n11p62

Online Published: June 21, 2017

\section{Abstract}

Background: Persistence, in academic settings, has been identified as a critical variable for success. Different than retention and attrition, persistence, as a personal characteristic, describes the student who progresses, despite opposition or importunity.

Methods: The Walker and Avant framework was used to guide the analysis of the concept of academic persistence, specifically as it applies to nursing education.

Results: Barriers to persisting, among nursing students, include academic and personal variables. As faculty, we are concerned with and responsible to provide interventions that address academic barriers to persistence; there is little we can, or should do with personal barriers.

Conclusions: Being able to identify the difference between academic and personal variables is the initial step in providing appropriate, and valued interventions.

Key Words: Persistence, Academic success, Nursing student

\section{INTRODUCTION}

Persistence, because of its link to academic success, has long been a focus area of higher education research. Within published research, persistence and retention are frequently used interchangeable. Retention, as an organizational phenomenon, is measured by the number of students returning and progressing toward degree completion. Retention strategies are organization-specific, guided by the demographics of the student population, and demonstrate an institutional commitment to the students. ${ }^{[1]}$ Students who continue to enroll are described as academically retained and reported as a primary indicator of institutional performance.

As an individual phenomenon, persistence describes the ability of a student to achieve their academic goal. Within academia, persistence is defined as a complex, multidimen- sional phenomena influenced by an interaction of personal, academic, and environmental factors. ${ }^{[2]}$ Persistence may be unrelated to actual knowledge acquisition. ${ }^{[3]}$ According to Ishler and associates ${ }^{[4]}$ preparation, ability, and motivation are constructs required for academic persistence. Strategies to affect each of these variables need to be individualized and specific to the challenge and the demographic characteristic of the student.

Bronstein $^{[5]}$ describes retention as an institutional measure and persistence as a student trait. The ability to separate these terms, and clearly define academic persistence within nursing education will allow nursing faculty to develop and provide interventions that are appropriately targeted, and aimed at improving academic persistence. Separating persistence from retention assures that the individualized intervention is de-

*Correspondence: Kimberly D. Kennel; Email: kimberly.kennel@bchs.edu; Address: Baptist College of Health Sciences, 1003 Monroe Ave Memphis, TN 38104, United States. 
veloped, provided, and assessed correctly.

Nursing student academic success has been linked to persistence. Despite the myriad of academic support programs, strategies, practices and interventions designed to enhance success as measured by persistence remains a challenge. ${ }^{[6]}$ Due to the ongoing nursing shortage and societal changes faculty need to examine how nursing students persist and what can be done to enhance their persistence. The study of persistence has been an ongoing problem in nursing and in earlier years was attributed to the problems of individual students. ${ }^{[6]}$ Outcomes associated with the inability to persist include personal (attrition), organizational (retention), societal (graduate), and financial (debt). Reason's ${ }^{[7]}$ Col- lege Experience Persistence Model, depicted in Figure 1, displays the influences which impacted student learning and persistence during the college experience. The model includes students' precollege characteristics and experiences including sociodemographic traits, academic preparation and performance and student dispositions. These are what the student brings as they enter the institution of higher learning. As the student becomes a part of the institution the model indicates how, individual student experiences can be classified into three distinct categories; classroom experiences: out-of-class experiences: and curricular experiences. Thus, for this concept analysis, these constructs which pertain to what happens to a student within a program of nursing will be used to define academic persistence for the nursing student.

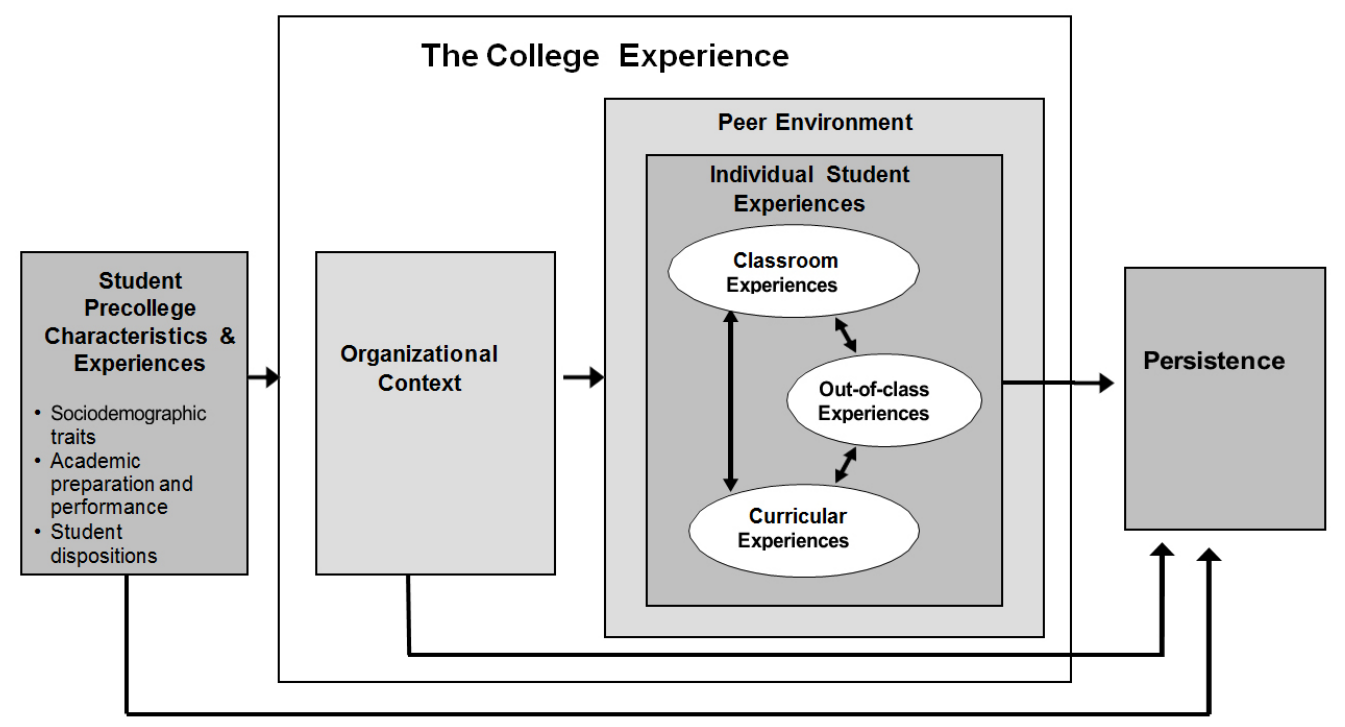

Figure 1. Reason's college experience persistence model

\section{METHODS}

\section{Purpose of a concept analysis}

Concept analyses are undertaken to examine the meaning and structure of a concept. ${ }^{[8]}$ This activity clarifies the defining characteristics of the concept, and allows for operational definitions to be devised. Walker and Avant ${ }^{[8]}$ provide a seven-step process for conducting a concept analysis. These steps include (1) selecting the concept, (2) determining the purpose of the analysis, (3) identifying all uses of the concept, (4) defining the attributes, (5) identifying a model case, (6) identifying consequences of the concept, and (7) defining empirical references of the concept. This framework was used to examine the concept. The purpose of using Walker and Avant's framework for concept analysis was to identify as many possible uses of the concept of academic persistence and to provide insight into the current issue of retention in programs of nursing.
The impetus for selection of the concept of persistence is due to the rigorous nature of nursing programs that require early assessment and intervention to enhance students' chances of achieving success in the nursing program, completing the program on schedule, and going on to pass the NCLEX-RN so that they may enter the nursing workforce. The concept under analysis is persistence, and the purpose of the analysis is to operationalize persistence among nursing students and to separate academic from personal persistence.

\section{Results}

\subsection{Identifying the uses of the concept}

To identify all uses of the concept, as required in step three, a literature search was conducted. Using the search engines of CINAHL, PubMed, ProQuest, Science Direct, Google Scholar, Psych Articles and Education Full Text and the keyword persistence numerous articles were identified. Adding 
nursing student, academic success, and student success as keywords, as well as focusing on research published in peerreviewed indexed journals, writing in English, readily available, and published between 2000 and 2015 resulted in 1,789 articles. Limiting the articles to those focusing on student persistence and the study population limited to those presently enrolled in higher educational programs resulted in 20 articles. These articles encompassed the literature review utilized for this concept analysis (see Table 1).

\subsection{Defining the attributes}

A person who persists has been defined as a person who "goes on resolutely or stubbornly despite opposition, importunity, or warning: one who continues firmly or obstinately". ${ }^{[9]}$ Someone who persists may be described as having grit, determination, or commitment. The antonym for retention is attrition, ${ }^{[10]}$ which is defined as a loss of students from a nursing program resulting in the difference between the numbers of students beginning a program to the numbers of students finishing the program. ${ }^{[10]}$ Thus, these definitions make it easy to differentiate the two terms. Retention is an institutional measure. However, persistence is an individual phenomenon as a student persists to a goal. ${ }^{[7]}$

The term persistence often evokes the reflection of an adversity that an individual overcomes during the pursuit of a goal or dream. ${ }^{[11]}$ Persistence may be observed as a characteristic that motivates a person; once a task is undertaken, persistence assures that the task will be satisfactorily completed. ${ }^{[12]} \mathrm{A}$ student who persists or has the quality of persistence is one who continues to enroll full-time and continuously pursue a degree with expectations of graduation. ${ }^{[5]}$ A persisting student has acquired the characteristics of academic aptitude, readiness, motivation, personality and student development. ${ }^{[9]}$ The outcome of persistence, per Bronstein, ${ }^{[5]}$ is graduation.

Within the profession of nursing, persistence is defined as an ability to overcome obstacles and successfully complete a course or program of study. ${ }^{[13]}$ Academic factors that affected persistence are circumstance-specific and may be either positive or negative. ${ }^{[14]}$ Persistence has also been described to include the student who "stops out" ${ }^{[15]}$ These students' complete courses on a flexible timetable. While ultimately these students may complete their degree, persistence, viewed as maintaining enrollment until graduation, is affected.

Persistence was initially identified in 1975 by Tinto $^{[16]}$ as a characteristic absent in students who exited institutions of higher education prior to graduation. Since its initial identification, Bean ${ }^{[17]}$ in 1980 amended the model to focus on attrition. Although both of these models highlight the im64 portance of student experiences on campus ${ }^{[15]}$ this analysis uses Reason's ${ }^{[7]}$ (2009) framework to clarify the concept of academic persistence. The individual student experiences that affect persistence are conceptualized as influences on student learning and subsequent persistence. ${ }^{[7]}$ Habley and associates ${ }^{[9]}$ described a persistent student as one who has acquired the characteristics of academic aptitude, commitment, readiness, motivation, engagement, and self-regulation. Raman ${ }^{[18]}$ posited that motivation, self-concept, and commitment have a positive effect on persistence. Tinto ${ }^{[1,16,19]}$ identified expectations, support, feedback, involvement, and learning as five conditions that facilitate persistence. $\operatorname{Hart}^{[14]}$ posited that that social connectedness, perceived stress and support, self-motivation, and goal attachment as contributers to persistence.

Reviewing the attributes identified in the literature provides the ability to identify personal modifiable attributes, or ones which may be amenable to interventions. ${ }^{[14]}$ Academic aptitude, readiness, self-regulation, and learning are nonmodifiable, and thus, while they impact persistence and ultimately academic success, interventions should not be aimed at increasing these characteristics. Thus, these attributes may be beyond the realm of an educational intervention. ${ }^{[20]}$ Student grades correlate to academic self-efficacy, which retain or enhance persistence. ${ }^{[21]}$ In fact, among all academic variables, grade point average (GPA) was determined to be the strongest predictor for student persistence. ${ }^{[22]}$ Persistence, viewed through these paradigms, is an antecedent to academic success. Reason' ${ }^{[7]}$ College Experience Persistence Model separates students' precollege characteristics and experiences as personal persistence attributes that cannot be altered by interventions. Characterizing academic persistence into individual student experiences provides opportunities to measure and evaluate persistence interventions in nursing education.

\subsection{Model case}

According to Walker and Avant, ${ }^{[8]}$ a model case demonstrates the defining attributes of the concept being analyzed and illustrates the use of that concept in a realistic situation. Amy, a junior in a baccalaureate nursing program, is about to start a difficult nursing course that requires substantial class, clinical, and lab requirements. This course has a 30\% drop, fail, withdraw (DFW) rate. Amy has heard from friends that this course is really tough. This seven credit hour course is Adult Medical Surgical Nursing and is the first course where she will provide direct patient care. There is course work, high stakes testing and clinical preparation. She has a 3.5/4.0 GPA in science courses and understands the rigor of nursing content. 
Table 1. Results of persistence literature review

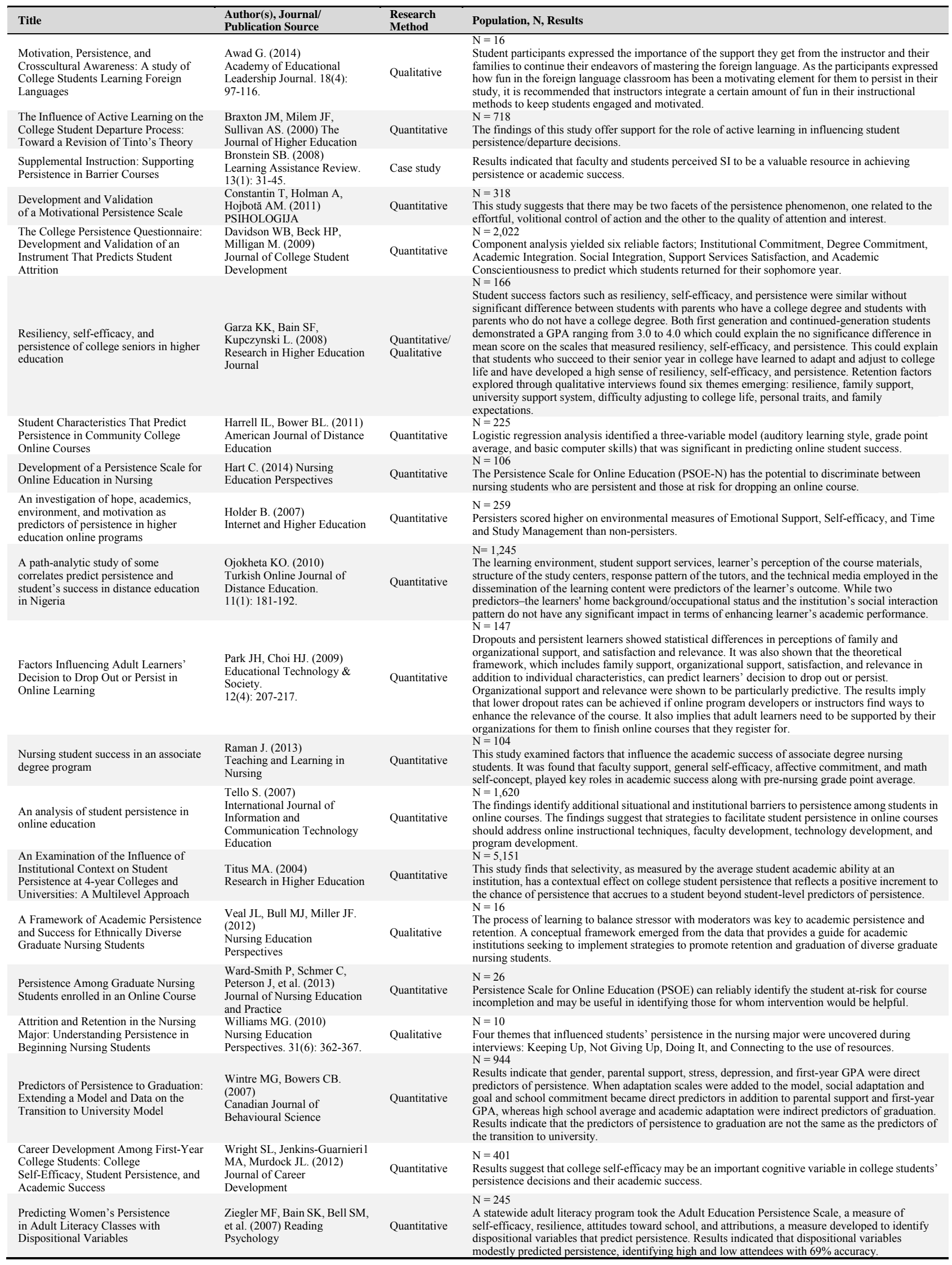


Amy is highly motivated and is committed to a life-long goal of becoming a nurse. She is ready for the challenge and has developed self-regulation by acquiring study skills to be successful. The student is engaged in campus activities including the use of academic support services such as supplemental instruction and individual peer tutoring. She attends all supplemental sessions and utilizes individual tutoring as needed. The student receives constructive feedback from the faculty and utilizes peer learning to clarify content. This active engagement is student centered and is promoted in and out of the classroom. The student persists in the nursing course and the program and achieves the outcome of academic success. ${ }^{[9,23]}$ This student has many attributes that describe academic persistence.

\subsection{Consequences of the concept}

Consequences are those events or incidences that occur as a result of the occurrence of the concept, in other words, the outcomes of the concept. ${ }^{[8]}$ Assuming that persistence is partially based on goals and commitments established prior to enrollment in a program of nursing, the link between academic persistence, participation in interventions and a successful academic outcome cannot be understated. While Tinto's (1975) ${ }^{[16]}$ Theory of Student Departure was developed to guide the study of attrition and retention in higher education, the theory had influence over persistence. In fact, empirical testing demonstrated effectiveness of educational interventions in empirical research and testing. ${ }^{[15]}$ This theory emphasized the role of campus-based interactions and integration on persistence.

\subsection{Empirical references of the concept}

Using the framework developed by Reason (2009), ${ }^{[7]}$ the empirical references focused on persistence will be separately reviewed, by construct. Thus, the relevant data related to classroom experiences, out-of-class experiences, and curricular experiences will be presented separately.

\subsubsection{Classroom experiences}

Classroom experiences have an important role for both student learning and persistence. Tinto ${ }^{[16]}$ initially identified academic integration as an indicator for persistence. When academic integration is absent, disappointment in the academic experience, decreased motivation, or dropping out occurs. Demaris and Kritsonis ${ }^{[13]}$ posited that engaging experiences, within the classroom, enhance academic persistence. Active learning course practices may directly influence social integration and indirectly affect subsequent institutional commitment and student departure decisions. ${ }^{[24]}$ Pedagogical practices that provide a cooperative learning environment are linked to persistence decisions. Passive practices of instruction were found to have a negative relationship to persistence. ${ }^{[24]}$

\subsubsection{Out-of-class experiences}

Out-of-class experiences, or what happens to a student after arrival on campus were initially identified by Pascarella and Terenzini in $1983^{[25]}$ as having a great impact on persistence. This perception was supported in 2013 by Burrus and associates, ${ }^{[15]}$ adding that out-of-class experiences have a greater importance than either the background characteristics, personal commitments, or the goal of graduation. According to Tinto, ${ }^{[16]}$ when experiences integrate the student socially and intellectually into the life of the institution, persistence toward graduation will occur. Out-of-class experiences are those that engage the student to campus life, and include participation in clubs, sports or other on campus activities. Conclusions from a meta-analysis study, ${ }^{[26]}$ identified on campus activities and academic organizations as influential to persistence. The results of this work also revealed a correlation between student involvement in on campus activities and graduation. Educationally purposeful out-of-classroom experiences, such service learning and learning communities, have been documented to have a positive effect on persistence when the student is from an ethnically or racially diverse background. ${ }^{[27]}$

\subsubsection{Curricular experiences}

Curricular experiences include formal, structured, facultydirected activities. Mentoring programs, led by faculty members, have been identified as having a positive influence on program completion. ${ }^{[28]}$ Faculty support, encouragement and interaction in the classroom were identified by Fleming ${ }^{[6]}$ as being essential components to nursing student's persistence even when academic work in the nursing program was difficult. These curricular program interventions may include first year transition programs, academic advising, counseling services, academic support programs, enrichment programs, tutoring and Supplemental Instruction (SI). ${ }^{[9]}$

Evaluating interventions aimed at enhancing persistence have used course grade or course drop rates. Jeffreys ${ }^{[29]}$ study described and evaluated select aspects of an enrichment program (EP) for students who participated in peer/mentor/tutor (PMT) led study groups throughout the semester. Despite the challenges that impact personal persistence, and the demographic variability among the students, those in the EP group had higher pass rates, lower failure rates, and lower withdrawal rates when compared with the control group. ${ }^{[2]}$ Research by Shelton ${ }^{[30]}$ concluded that perceived faculty support correlated to persistence, academic performance, and graduation. 


\subsection{Assessing persistence}

According to Walker and Avant, ${ }^{[8]}$ empirical referents provide a means of measuring the degree of existence of a concept. Empirical referents for the concept persistence as an outcome may include student grades and/or pass/fail. Persistence in higher education or programs of nursing, has also been measured, or self-assessed, using a variety of Likerttype instruments. Constantin and associate ${ }^{[12]}$ developed a motivational persistence scale that evaluated long and short term commitments. Higher education has measured persistence and/or retention with the National Survey of Student Engagement and the Noel Levitz College Student Inventory. ${ }^{[9]} \mathrm{Harr}^{[14]}$ measured the self-assessed persistence of online nursing students with a psychometric tool called the Persistence Tool for Online Education. Unfortunately, there is neither agreement on the definition of academic persistence, nor on the method used to assess academic persistence, which varies from study to study. Nursing education has not evaluated persistence within the context of academic support programs.

Other persistence-focused instruments have been developed for specific populations, such as a scale for measuring persistence in children. ${ }^{[31]}$ Persistence has also been measured in psychology research with specific scales or components of multiphasic questionnaires (Temperament and Character Inventory, ${ }^{[32]}$ Self-Control Measure). ${ }^{[33]}$ Other instruments which measure or assess persistence emphasize sustained involvement in an activity, ${ }^{[12]}$ renewal of commitment ${ }^{[18]}$ and intensification of effort when facing obstacles. ${ }^{[31]}$ The Adult Persistence Scale, developed by educators, has demonstrated reliability in predicting persistence in those enrolled in adult literacy courses. ${ }^{[34]}$

\section{Disscussion AND CONCLUSION}

\section{Summary and next steps}

Persistence, as an academic and personal concept, is a phenomenon experiencing international concern among institutions of higher education. Within nursing, student academic persistence has an economic impact for academia, and affects the availability of future nurses. ${ }^{[35]}$ According to Ooms and colleagues, ${ }^{[36]}$ many faculty members view persistence as the responsibility of the learner. Yet data demonstrates that interventions aimed at improving academic persistence are effective. Reinhardt and associates ${ }^{[37]}$ posited that developing and providing academic interventions are specifically important for faculty of nursing programs, which have higher than normal attrition rates due to the rigor of content.

Academic persistence has been described in many ways. Hart $^{[14]}$ and Ward-Smith and colleagues ${ }^{[20]}$ operationally defined persistence as a student characteristic or attitude. Thus, academic persistence can be measured and altered, using interventions aimed at overcoming obstacles or hardships that prevent the student from course completion. Persistence, as a concept, has been used as the variable measured to determine the effect of sustained involvement in a course or program, the renewal of career commitment, and the result of intensification of effort when facing obstacles. Separating academic persistence from personal persistence provides clarity for research, assuring that any intervention and any outcome measures are appropriate.

\section{CONFLicts OF INTEREST Disclosure}

The authors declare there is no conflict of interest.

\section{REFERENCES}

[1] Tinto V. Leaving college: rethinking the causes and cures of student attrition. University of Chicago Press; 1993.

[2] Jeffreys MR. Students' perceptions of variables influencing retention: a pretest and post-test approach. Nurse Educator. 2002; 27(1): 16-19. https://doi.org/10.1097/00006223-200201000-00013

[3] Park JH, Choi HJ. Factors influencing adult learners' decision to drop out or persist in online learning. Educational Technology \& Society. 2009; 12(4): 207-217.

[4] Ishler JLC, Upcraft ML. Challenging and supporting the first-year student: a handbook for improving the first year of college. Philadelphia: Jossey-Bass Publisher; 2014. 27 p.

[5] Bronstein SB. Supplemental Instruction: supporting persistence in barrier courses. Learning Assistance Review. 2008; 13(1): 31-45.

[6] Fleming KL. Student persistence in associate degree nursing programs at Mississippi community colleges [dissertation]. The Univer- sity of Southern Mississippi; 2010. Available from: http://aqui la.usm.edu/dissertations/524

[7] Reason RD. An examination of persistence research through the lens of a comprehensive conceptual framework. Journal of College Student Development. 2009; 50(6): 659-682. https://doi.org/10 $.1353 / \mathrm{csd} .0 .0098$

[8] Walker LO, Avant KC. Strategies for Theory Construction in Nursing. 5th edition. Boston: Prentice Hall; 2011.

[9] Habley WR, Bloom JL, Robbins SB. Increasing persistence. San Francisco, CA: Jossey-Bass; 2012.

[10] Urwin S, Stanley R, Jones M, et al. Understanding student nurse attrition: learning from the literature. Nurse Education Today. 2010; 30(2): 202-207. https://doi.org/10.1016/j.nedt.2009.07 .014

[11] Merriam-Webster Dictionary. 2016. Persistence. Available from: http://www.merriam-webster.com/dictionary/persiste nce

Published by Sciedu Press 
[12] Constantin T, Holman A, Hojbotă M. Development and validation of a motivational persistence scale. Psihologija. 2012; 45(2): 99-120. https://doi.org/10.2298/PSI1202099C

[13] Demaris MC, Kritsonis WA. The classroom: Exploring its effects on student persistence and satisfaction. Focus on Colleges, Universities, and Schools. 2008; 2(1): 1-9. Available from: https: //eric.ed.gov/?id=ED501268

[14] Hart C. The persistence scale for online education: Development of a psychometric tool [dissertation]. University of Missouri-Kansas City; 2012.

[15] Burrus J, Elliott D, Brenneman M, et al. Putting and keeping students on track: toward a comprehensive model of college persistence and goal attainment. 2013. Available from: https://www. ets.org/Media/Research/pdf/RR-13-14.pdf https://doi. org $/ 10.1002 / j .2333-8504.2013$.tb02321. $x$

[16] Tinto V. Dropout from higher education: a theoretical synthesis of recent research. Review of Educational Research. 1975; 45(1): 89-125. https://doi.org/10.3102/00346543045001089

[17] Bean JP. Dropouts and turnover: the synthesis and test of a causal model of student attrition. Research in Higher Education. 1980; 12(2): 155-187. https://doi.org/10.1007/BF00976194

[18] Raman J. Nursing student success in an associate degree program. Teaching and Learning in Nursing. 2013; 8(2): 50-58. https: //doi.org/10.1016/j.teln.2012.12.001

[19] Tinto V. Research and practice of student retention: What next? Journal of College Student Retention: Research, Theory \& Practice. 2006; 8(1): 1-19. https://doi.org/10.2190/COC4-EFT9-EG7 W-PWP4

[20] Ward-Smith P, Schmer C, Peterson J, et al. Persistence among graduate nursing students enrolled in an online course. Journal of Nursing Education and Practice. 2013; 3(9): 48-52. https: //doi.org/10.5430/jnep.v3n9p48

[21] Garza KK, Bain SF, Kupczynski L. Resiliency, self-efficacy, and persistence of college seniors in higher education. Research in Higher Education Journal. 2014; 26: 1-20. https://doi.org/10.1177/ 1538192710380744

[22] Ojokheta KO. A path-analytic study of some correlates predicting persistence and student's success in distance education in Nigeria Turkish Online Journal of Distance Education. 2010; 11(1).

[23] Jeffreys MR. Nursing Student Retention. New York, NY: Springer; 2012.

[24] Braxton JM, Milem JF, Sullivan AS. The influence of active learning on the college student departure process: Toward a revision of Tinto's theory. Journal of Higher Education. 2000; 71(5): 569-590. https://doi.org/10.2307/2649260

[25] Pascarella ET, Terenzini PT. Predicting voluntary freshman year persistence/withdrawal behavior in a residential university: A path analytic validation of Tinto's model. Journal of Educational Psychology. 1983; 75(2): 215-226. https ://doi .org/10.1037/0022-0 663.75 .2 .215

[26] Robbins SB, Lauver K, Le H, et al. Do Psychosocial and Study Skill Factors Predict College Outcomes? A Meta-Analysis. Psychological Bulletin. 2004; 130(2): 261-288. PMid:14979772 https: //doi.org/10.1037/0033-2909.130.2.261

[27] Kuh GD, Cruce TM, Shoup R, et al. Unmasking the effects of student engagement on first-year college grades and persistence. The Journal of Higher Education. 2008; 79(5): 540-563. https: //doi.org/10.1353/jhe.0.0019

[28] Miller CL, Leadingham C. A formalized mentoring program for LPN-to-RN students. Teaching and Learning in Nursing. 2010; 5(4): 149-153. https://doi.org/10.1016/j.teln.2010.03.002

[29] Jeffreys MR. Evaluating enrichment program study groups: academic outcomes, psychological outcomes, and variables influencing retention. Nurse Educator. 2001; 26(3): 142-149. https ://doi .org/10 .1097/00006223-200105000-00017

[30] Shelton EN. A model of nursing student retention. International Journal of Nursing Education Scholarship. 2012; 9(1): 1-16. https: //doi.org/10.1515/1548-923X.2334

[31] Lufi D, Cohen A. A scale for measuring persistence in children. Journal of Personality Assessment. 1987; 51(2): 178-185. https: //doi.org/10.1207/s15327752jpa5102_2

[32] Cloninger CR, Svrakic DM, Przybeck TR. A psychobiological model of temperament and character. Archives of General Psychiatry. 1993; 50(12): 975-990. https://doi.org/10.1001/archpsyc. 1993. 01820240059008

[33] Tangney JP, Baumeister RF, Boone AL. High Self-Control predicts good adjustment, less pathology, better grades, and interpersonal success. Journal of Personality. 2004; 72(2): 271-324. https://doi.org/10.1111/j.0022-3506.2004.00263.x

[34] Ziegler MF, Bain SK, Bell SM, et al. Predicting women's Persistence in adult literacy classes with dispositional variables. Reading Psychology. 2007; 27(1): 59-85. https://doi.org/10.1080/0270 2710500542668

[35] Lancia L, Petrucci C, Giorgi F, et al. Academic success or failure in nursing students: results of a retrospective observational study. Nurse Education Today. 2013; 33(12): 1501-1505. https : //doi.org/10.1016/j.nedt.2013.05.001

[36] Ooms A, Fergy S, Marks-Maran D, et al. Providing learning support to nursing students: a study of two universities. Nurse Education in Practice. 2013; 13(2): 89-95. http://doi.org/10.1016/j.nepr .2012 .07 .011

[37] Reinhardt AC, Keller T, Ochart Summers L, et al. Strategies for success: crisis management model for remediation of at-risk students. Journal of Nursing Education. 2012; 51(6): 305-11. https : //doi.org/10.3928/01484834-20120409-03 